\title{
Review
}

Fetal Diagnosis

and Therapy
Fetal Diagn Ther 2014;36:162-165

DOI: $10.1159 / 000358058$
Received: December 8, 2013

Accepted: December 9, 2013

Published online: January 25, 2014

\section{Fetal Growth Restriction at the Limits of Viability}

\author{
Gerard H.A. Visser $^{\mathrm{a}}$ Caterina M. Bilardo ${ }^{\mathrm{b}}$ Christopher Lees $^{\mathrm{c}}$ \\ ${ }^{a}$ Departments of Obstetrics, University Medical Center, Utrecht, and ${ }^{b}$ University of Groningen, \\ Groningen, The Netherlands; ${ }^{C}$ Imperial College, London, UK
}

\section{Key Words}

Fetal growth restriction - Intrauterine growth-restricted fetuses · Limits of viability - Small-for-gestational age

\begin{abstract}
The outcome of early small-for-gestational age and/or intrauterine growth-restricted fetuses is reviewed. In these fetuses the outcome appears to be considerably poorer than that of appropriately grown fetuses and this seems mainly to be caused by intrauterine malnutrition rather than by hypoxemia. Active management of intrauterine growth restriction at the limits of viability may not be commenced before 26 weeks of gestation.

(c) 2014 S. Karger AG, Basel
\end{abstract}

\section{Introduction}

In the course of the years perinatal survival has improved, especially at younger gestational ages. This has resulted in a more active approach at the limits of viability and in developed countries such an approach is generally being taken from around 24 weeks of gestation onwards. However, the question arises as to whether this should hold for all fetal weight for gestational age percentiles, since (intact) survival may well depend on the presence or otherwise of early placental insufficiency and fetal growth restriction. This issue will be addressed in this paper.

\section{KARGER}

E-Mail karger@karger.com

www.karger.com/fdt

\section{Incidence of Small-for-Gestational Age and/or Fetal Growth Restriction at Early Gestation}

Small-for-gestational age (SGA) refers to the birth weight of an infant in relation to that of all infants born at the same gestational age, whereby SGA is usually defined as a weight below the 10th centile. Fetal intrauterine growth restriction (IUGR) is still frequently used as a synonym for SGA, but relates to a different condition, namely a fetal growth pattern below its potential due to an impaired placental development. More recently, the TRUFFLE group defined fetal growth restriction as the combination of fetal smallness (abdominal circumference $<10$ th centile) and a functional assessment of abnormal feto-placental perfusion, namely umbilical artery pulsatility index $>95$ th centile [1]. This definition has been endorsed more recently by the PORTO group, who in a large prospective study of fetal growth restriction found that abnormal umbilical artery Doppler and EFW $<10$ th percentile were strongly and most consistently associated with a composite adverse perinatal outcome [2].

This means that many SGA fetuses may not be growthrestricted but are just constitutionally small, whereas many infants with a birth weight $>10$ th centile may in fact have been growth-restricted. The latter seems to hold true, especially at early gestational ages. This may be concluded when comparing median birth weight of infants born at a certain gestational age with that of intrauterine growth charts which are based on ultrasound measure-
(C) 2014 S. Karger AG, Basel

$1015-3837 / 14 / 0362-0162 \$ 39.50 / 0$
Prof. Dr. Gerard H.A. Visser

Department of Obstetrics

University Medical Center, Lundlaan 6

NL-3584 EA Utrecht (The Netherlands)

E-Mail g.h.a.visser@umcutrecht.nl 


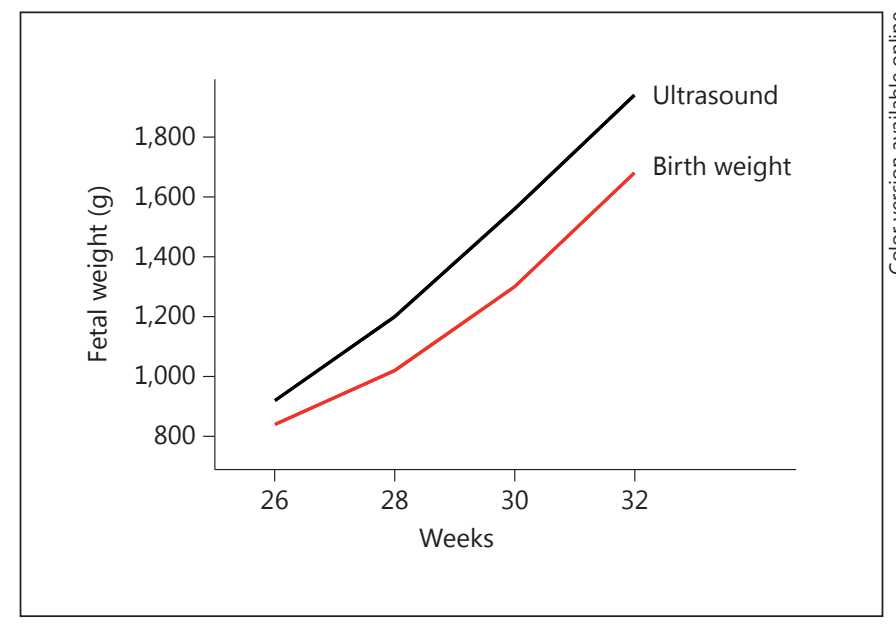

Fig. 1. Median fetal weight according to ultrasound measurements [3] as compared to the median weight of infants born preterm [4].

ments of ongoing pregnancies $[3,4]$. During the second trimester, median weight in the former group is about $200 \mathrm{~g}$ lower than that based on intrauterine growth charts (fig. 1). Such a difference is absent near term. The inference is that at early gestation many more infants born at that particular gestation may have had intrauterine growth problems than might have been expected according to the birth weight centiles. Moreover, perinatal survival during the second trimester is highest in infants with a birth weight around the 90th centile, also suggesting impaired development in infants with a lower weight [5]. However, it should be noted that the latter also holds true for survival during the third trimester, although at that age most infants, also the small ones, survive $[6,7]$.

All in all, we may conclude that at the limits of viability more babies are born with abnormal growth than would be expected from the birth weight statistics. Let us now discuss the prognosis of SGA and/or IUGR infants born at early gestational ages.

\section{Prognosis of SGA Infants Born before 28 Weeks of Gestation}

The prognosis of infants born very preterm in relation to birth weight centiles has been calculated by different groups in so-called PREM scores [5, 8]. All scores show that survival gradually decreases with decreasing weight centiles. Survival rates of children with a birth weight at the $2.3 \mathrm{rd}$ centile are the same as those of chil- dren with a birth weight at the 50th centile but with a 2 -week shorter gestational age at delivery. Other studies have shown that odds ratios for neonatal mortality in SGA infants born between 24 and 29 weeks are between 2 and 4 as compared to appropriately grown infants, with a concomitant increase in neurological and other morbidities [9-12]. In one large European study it was found that also a birth weight between the 10th and 25 th centile was associated with a twofold increase in mortality as compared to infants with a weight in the $50-75$ th centile range [13]. Thus, in case active management is generally started from 24 weeks onwards, one might consider starting 2 weeks later in case of an SGA infant.

\section{Prognosis of IUGR Infants Born before 31 Weeks of Gestation}

It is still difficult to define IUGR based on clinical signs. However, there is now an emerging consensus from the TRUFFLE and PORTO studies that the combination of SGA with abnormal Doppler flow velocity waveform patterns in the umbilical artery represents true fetal growth restriction $[1,2]$. Thus far there are three observational studies using these criteria in which neonatal outcome and/or outcome at 2 years of age have been reported according to the gestational age at delivery (table 1). Data on (intact) neonatal survival in these studies were based on deliveries between the years 2000-2006 [14] and 2005-2010 [1], respectively, and those on (intact) survival at 2 years of age on deliveries between 1997 and 2004 [15]. These studies included patients who were delivered before 34 weeks $[14,15]$, or included in the study before 32 weeks [1]. Data reported in table 1 are restricted to deliveries before 31 weeks only; exact numbers at the different gestational ages were not reported in the original studies.

Neonatal survival increased from $13 \%$ at 24 weeks (one study only) to $43 \%$ at 25 weeks (one study) and to $58-76 \%$ at 26 weeks of gestation. At 30 weeks, neonatal survival was about $90 \%$, with the best results in the most recent study [1]. Intact neonatal survival was defined as neonatal survival without serious morbidity such as bronchopulmonary dysplasia, intraventricular hemorrhage grade 3 and 4 and necrotizing enterocolitis. At 24 weeks there were no intact neonatal survivors (one study), at 25 weeks, $13 \%$ (one study) and at 26 weeks, 6-31\%. At 30 weeks, intact neonatal survival ranged from 59 to $73 \%$. 
Table 1. Neonatal survival, neonatal survival without severe morbidity, survival at 2 years of age and intact survival at 2 years of age of IUGR fetuses with an abnormal Doppler in the umbilical artery, according to three observational studies (\% values)

\begin{tabular}{|c|c|c|c|c|}
\hline Week & $\begin{array}{l}\text { Neonatal } \\
\text { survival }\end{array}$ & $\begin{array}{l}\text { Intact } \\
\text { neonatal } \\
\text { survival }\end{array}$ & $\begin{array}{l}\text { Survival } \\
\text { at } 2 \text { years } \\
\text { of age }\end{array}$ & $\begin{array}{l}\text { Intact } \\
\text { survival } \\
\text { at } 2 \text { years }\end{array}$ \\
\hline 24 & 13 & 0 & & \\
\hline 25 & 43 & 13 & & \\
\hline \multirow[t]{3}{*}{26} & 58 & 31 & & \\
\hline & 76 & 6 & & \\
\hline & & & 35 & 0 \\
\hline \multirow[t]{3}{*}{27} & 68 & 27 & & \\
\hline & 83 & 15 & & \\
\hline & & & 76 & 46 \\
\hline \multirow[t]{3}{*}{28} & 78 & 52 & & \\
\hline & 93 & 32 & & \\
\hline & & & 81 & 57 \\
\hline \multirow[t]{3}{*}{29} & 86 & 62 & & \\
\hline & 93 & 35 & & \\
\hline & & & 78 & 60 \\
\hline \multirow[t]{3}{*}{30} & 84 & 73 & & \\
\hline & 97 & 59 & & \\
\hline & & & 88 & 64 \\
\hline
\end{tabular}

Data on neonatal survival from Baschat et al. [14], data at 24 and 25 weeks and first line at other ages, and Lees et al. [1], second line from 26 weeks onwards. Data on survival at 2 years from Torrance et al. [15].

Survival at 2 years of age increased from $35 \%$ at 26 weeks to $88 \%$ at 30 weeks (one study). Intact survival at 2 years of age was none of the 11 infants born at 26 weeks, $46 \%$ at 27 weeks and $64 \%$ at 30 weeks. All surviving infants with abnormal development had a developmental quotient (Griffiths test) or mental developmental index (Bayley test) $<85$; there was only 1 case with cerebral palsy.

Two studies have compared the outcome of IUGR infants with abnormal Doppler waveform patterns, born before 30 weeks of gestation, with matched appropriatefor-gestational age (AGA) infants. A German study, including 40 matched pairs born between 1990 and 1997, showed a lower neonatal survival (65 vs. $97.5 \%)$ and a higher rate of chronic lung disease, retinopathy grade 3-4 and impaired intestinal motility. Follow-up in 16 pairs showed a higher rate of cognitive impairment (44 vs. $25 \%)$ and a higher rate of severe motor impairment (38 vs. 19\%) in the IUGR group as compared to the controls [16]. A Swedish study on 42 matched pairs born between
1998 and 2204 at a median age at delivery of 27 weeks, showed a similar survival in the IUGR as compared to AGA infants ( $90 \%$ at 2 years of age), but a higher incidence of chronic lung disease, reduced lung function, increased cognitive impairment and higher incidence of structural vessel wall abnormalities at early school age in the IUGR group [17-20].

In conclusion, all except one of the studies on the outcome of early IUGR infants showed a high perinatal mortality. Moreover, neonatal and long-term morbidity were high and higher than in AGA preterm infants.

\section{Concluding Remarks}

Survival and longer term outcome of either SGA or IUGR infants born before 31 weeks is considerably poorer than that of AGA preterm infants. Data of IUGR infants born before 26 weeks show a very poor neonatal outcome and the same holds for the outcome at 2 years of age of infants born at 26 weeks. However, the latter two data concerned only two studies. Nevertheless, when including the data on the outcome in SGA infants and the fact that their outcome is comparable to that of AGA infants born at a 2-week shorter gestational age, one may suggest that active intervention by delivery of early IUGR fetuses, with or without concomitant maternal preeclampsia, should not be recommended before 26 weeks of gestational age, unless the parents decide otherwise. It may be more appropriate to allow the baby to gain gestational maturity even while running a high risk of intrauterine death, given that delivery itself would very likely be associated with a poor outcome. This management is informed by knowing that the outcome in a subsequent pregnancy is generally better $[21,22]$ and may be further improved by aspirin therapy started in the first trimester of a subsequent pregnancy.

Nowadays cerebral palsy does not seem to be higher in early IUGR infants as compared to AGA preterm infants $[15,17,23]$. This interesting observation may suggest that neurological morbidity is more likely to be caused by severe intrauterine malnutrition than by hypoxemia. A timely delivery before the occurrence of acidemia may have been instrumental. On the other hand, intrauterine treatment of malnutrition is currently impossible which hampers further improvements in the outcome. Though no specific treatments exist for IUGR, prevention of early IUGR and preeclampsia offers some promise through screening in early pregnancy and treatment of screenpositive cases with aspirin. 
In preterm IUGR fetuses with abnormal fetal Dopplers, indices of fetal lung maturation (lecithin/sphingomyelin ratio and laminar body count) have been found to be higher than in fetuses with normal Doppler waveform patterns [24], suggesting accelerated lung maturation in case of placental insufficiency. The fact that neonatal and later pulmonary problems seem higher in these infants than in AGA newborns may indicate a negative effect of malnutrition on lung development, comparable to that of neurological development. There is no evidence that antenatal corticosteroids improve the outcome in early IUGR infants, although proper randomized controlled trials are lacking [25].

\section{References}

1 Lees C, Marlow N, Arabin B, Bilardo CM, Brezinka C, Derks JB, et al: Perinatal morbidity and mortality in early-onset fetal growth restriction: cohort outcomes of the trial of randomized umbilical and fetal flow in Europe (TRUFFLE). Ultrasound Obstet Gynecol 2013;42:400-408.

-2 Unterscheider J, Daly S, Geary MP, Kennelly MM, McAuliffe FM, O’Donoghue K, Hunter A, Morrison JJ, Burke G, Dicker P, Tully EC, Malone FD: Optimizing the definition of intrauterine growth restriction: the multicenter prospective PORTO study. Am J Obstet Gynecol 2013;208:290.e1-e6.

-3 Hadlock FP, Harrist RB, Carpenter RJ, Deter RL, Parl SK: Sonographic estimation of fetal weight. The value of femur length in addition to head and abdomen measurements. Radiology 1984;150:535-540.

- 4 Visser GHA, Eilers PHC, Elferink-Stinkens PM, Merkus HMWM, Wit JM: New Dutch reference curves for birthweight by gestational age. Early Hum Dev 2009;85:737-744.

$\checkmark 5$ Cole TJ, Hey E, Richmond S: The PREM score: a graphical tool for predicting survival in preterm birth. Arch Child Fetal Neonatal Ed 2010;95:F14-F19.

6 Glinianaia SV, Rankin J, Pearce MS, Parker L, Pless-Mulloli T: Stillbirth and infant mortality in singletons by cause of death, birthweight, gestational age and birthweight-forgestation, Newcastle upon Tyne 1961-2000. Paediatr Perinat Epidemiol 2010;24:331-342.

7 Vangen S, Stoltenberg C, Skjaerven R, Magnus P, Harris JR, Stray-Pedersen B: The heavier the better? Birthweight and perinatal mortality in different ethnic groups. Int J Epidemiol 2002;31:654-660.

-8 Bader D, Kugelman A, Boyko V, Levitzki O, Lerner-Geva L, Riskin A, et al: Risk factors and estimation tool for death among extremely premature infants; a national study. Pediatrics 2010;125:696-703. $\checkmark$ Bernstein IM, Horbar JD, Badger GJ, Ohlsson A, Golan A: Morbidity and mortality among very-low-birth-weight neonates with intrauterine growth restriction. Am J Obstet Gynecol 2000;182:198-206.

10 Regev RH, Lusky A, Dolfin T, Litmanovitz I, Arnon S, Reichman B: Excess mortality and morbidity among small-for-gestational-age premature infants: a population-based study. J Pediatr 2003;143:186-191.

-11 Westby Wold SH, Sommerfelt K, Reigstad H, Ronnestad A, Medbo S, Farstad T, et al: Neonatal mortality and morbidity in extremely preterm small for gestational age infants: a population-based study. Arch Child Fetal Neonatal Ed 2009;94:F363-F367.

12 De Jesus LC, Pappas A, Shankaran S, Li L, Bell EF, Stoll BJ, et al: Outcomes of small for gestational age infants born at $<27$ weeks' gestation. J Pediatr 2013;163:55-60.

13 Zeitlin J, El Ayoubi M, Jarreau PH, Draper ES, Blondel B, Kunzel W, et al: Impact of fetal growth restriction on mortality and morbidity in a very preterm birth cohort. J Pediatr 2010;157:733-739.

14 Baschat AA, Cosmi E, Bilardo CM, Wolf H, Berg C, Rigano S, et al: Predictors of neonatal outcome in early-onset placental dysfunction. Obstet Gynecol 2007;109:253-261.

15 Torrance HL, Bloemen MCT, Mulder EJH, Nikkels PGJ, Derks JB, de Vries LS, Visser GHA: Predictors of outcome at 2 years of age after early intrauterine growth restriction. Ultrasound Obstet Gynecol 2010;36:171-177.

16 Vossbeck S, Kraus de Camargo O, Grab D, Bode H, Pohlandt F: Neonatal and neurodevelopmental outcome in infants born before 30 weeks of gestation with absent or reversed end-diastolic flow velocities in the umbilical artery. Eur J Pediatr 2001;160:128-134.
17 Brodzki J, Morsing E, Malcus P, Thuring A, Ley D, Marsal K: Early intervention in management of very preterm growth-restricted fetuses: 2 -year outcome of infants delivered before 30 gestational weeks. Ultrasound Obstet Gynecol 2009;34:288-296.

18 Morsing E, Asard M, Ley D, Stjernqvist K, Marsal K: Cognitive function following intrauterine growth restriction and very preterm birth. Pediatrics 2011;127:874-882.

19 Morsing E, Gustafsson P, Brodzki J: Lung function in children born after fetal growth restriction and very preterm birth. Acta Paediatr 2012;101:48-54.

-20 Morsing E, Liuba P, Fellman V, Marsal K, Brodzki J: Cardiovascular function in children born very preterm after intrauterine growth restriction with severely abnormal umbilical artery blood flow. Eur J Prev Cardiol 2013, Epub ahead of print.

21 Visser GHA, Huisman A, Saathof PWF, Sinnige HAM: Early fetal growth retardation: obstetric background and recurrence rate. $\mathrm{Ob}-$ stet Gynecol 1986;67:40-43.

-22 Sep S, Smits L, Prins M, Peeters L: Prediction tests for recurrent hypertensive disease in pregnancy, a systematic review. Hypertens Pregnancy 2010;29:206-230.

23 Jacobsson B, Ahlin K, Francis A, Hagberg G, Hagberg H, Gardosi J: Cerebral palsy and restricted growth status at birth: populationbased case-control study. BJOG 2008; 115 : 1250-1255.

24 Torrance HL, Voorbij HAM, Wijnberger LD, van Bel F, Visser GHA: Lung maturation in small for gestational age fetuses from pregnancies complicated by placental insufficiency or maternal hypertension. Early Hum Dev 2008;8:465-469.

25 Torrance HL, Derks JB, Scherjon SA, Wijnberger LD, Visser GHA. Is antenatal steroid treatment effective in preterm IUGR fetuses? A review of the literature. Acta Obstet Gynecol Scand 2009;88:1068-1073. 